Article

\title{
Effects of Biodegradation on the Structure and Properties of Windmill Palm (Trachycarpus fortunei) Fibers Using Different Chemical Treatments
}

\author{
Changjie Chen ${ }^{1,2}$, Weiwei Yin ${ }^{1}$, Guicui Chen ${ }^{1,3}$, Guangxiang Sun ${ }^{1}$ and Guohe Wang ${ }^{1,2, *}$ \\ 1 College of Textile and Clothing Engineering, Soochow University, Suzhou 215006, China; \\ ccjsd2013@163.com (C.C.); 20154215008@stu.suda.edu.cn (W.Y.); 20154015008@stu.suda.edu.cn (G.C.); \\ 20145215010@stu.suda.edu.cn (G.S.) \\ 2 Nantong Textile \& Silk Industrial Technology Research Institute, Nantong 226108, China \\ 3 Jiangsu Research and Development Center of the Ecological Textile Engineering and Technology, Yancheng \\ Institute of Industry Technology, Yancheng 224005, China \\ * Correspondence: wangguohe@suda.edu.cn; Tel.: +86-132-9511-8006
}

Academic Editor: Yong Sheng

Received: 21 March 2017; Accepted: 5 May 2017; Published: 9 May 2017

\begin{abstract}
In this work, windmill palm fiber (WPF), alkali-treated fiber (AF) without hemicellulose and bleached fiber (BF) without lignin were prepared and buried in soil for 30, 60 and 90 days. The surface morphology, chemical composition, crystallinity degree, mechanical properties, and residual mass rate of the samples, before and after biodegradation, were investigated. According to the results, soil burial degradation can remove the parenchyma cells and silica-bodies of WPF and deplete droplets containing the lignin of alkali-treated fiber after it has been buried for 30 days (AF30), and degradation of the single fiber cell wall of bleached fiber after it has been buried for 30 days (BF30). Buried in natural soil, lignin has a slower degradation rate than that of hemicellulose. WPF showed no significant differences in tensile strength after burial in soil for 90 days, because of the integrity fiber structure decreased the biodegradation. The most serious decrease, about $43 \%$, in tensile strength occurred in AF after it had been buried for 90 days (BF90). This basic knowledge may be helpful for windmill palm fiber applications, especially for biodegradable composites.
\end{abstract}

Keywords: windmill palm fiber; alkali-treated fiber; bleached fiber; biodegradation; mechanical property

\section{Introduction}

Cellulose, a dominant component in the vast majority of plant forms, which has an annual production that is estimated to be around $1.0 \times 10^{11} \sim 1.0 \times 10^{12} \mathrm{t}[1-3]$, is a promising resource. In particular, annually renewable agricultural residues represent an abundant, inexpensive, and readily-available source of renewable lignocellulosic biomass [4]. Increased attentions have been given to the production of novel materials for environmentally-friendly industrial use, post chemical modification [5]. Sodium chlorite $\left(\mathrm{NaClO}_{2}\right)$ treatment is a common method for the bleaching of fibers. The oxidation reaction can form chlorine dioxide $\left(\mathrm{ClO}_{2}\right)$, which reacts with lignin constituents, and, thus, lignin is removed from fiber [6-8]. Alkali treatment is also a useful method of eliminating amorphous hemicellulose in order to improve the mechanical properties of lignocellulose fiber [9-11].

Composite materials are one of the most significant inventions of the material sciences, which can be used in many fields, and have high-quality and low-cost applications [12]. The due criticism of synthetic reinforcement of composites is that they are not easily biodegradable. In recent years, there has been tremendous growth in the study and development of natural fiber-reinforced composite materials [13]. Among reinforcing fibers, palm fiber appears to be a promising material because it is 
relatively inexpensive and abundantly available. Windmill palm fiber is part of the palm fiber family and has abundant lignocellulose materials. Presently, in China, most of the abundant, inexpensive, and readily-available windmill palm leaf sheaths are treated as waste or as fuel, which creates environmental-pollution problems. Some of the leaf sheaths are used to make mattress and other products of low additional value and low efficiency, such as whisk brooms brushes and ropes [14]. However, windmill palm fiber has a tensile strength that is equal to that of surge palm [15], and has the potential to be used as a reinforcement fiber to make biodegradation composites. Studies on biodegradation behavior are important for the application of windmill palm fiber as a reinforcement fiber for biodegradable composites in environmental aging.

This paper focuses on the properties of windmill palm fibers (WPF), alkali-treated windmill palm fibers (AF), and bleached windmill palm fibers (BF), before and after soil burial degradation. The effects of biodegradation on morphology structure, chemical composition, crystallinity degree, and the mechanical properties of the fibers, with and without chemical treatment, are studied. The goal of this study is to provide background information that will hopefully be of use in future fiber applications, especially in biodegradable composites.

\section{Materials and Methods}

\subsection{Materials}

Untreated windmill palm fiber was drawn off of a mesh that was obtained from the Yuanmu Company in Hubei province, China. The bleached fiber was prepared using a $0.007 \mathrm{M} \mathrm{NaClO}_{2}$ solution and $0.022 \mathrm{M} \mathrm{CH}_{3} \mathrm{COOH}$ with a water bath of 1:50 (fiber-to-liquor ratio) for $2 \mathrm{~h}$ at $80{ }^{\circ} \mathrm{C}$ for 3 times [16]. The raw windmill palm fiber was soaked in $1.5 \mathrm{M}, 2 \mathrm{M}$ and $2.5 \mathrm{M} \mathrm{NaOH}$ solutions, one at a time, in a water bath of 1:50. The temperature was maintained at $60^{\circ} \mathrm{C}$ for $2 \mathrm{~h}$ to prepare the alkali-treated fiber [15].

Untreated WPF, after biodegradation in soil for 30, 60, and 90 days, were WPF30, WPF60 and WPF90, respectively; alkali-treated fiber, after biodegradation in soil for 30, 60 and 90 days, were AF30, AF60 and AF90, respectively; and bleached fiber, after biodegradation in soil for 30, 60, and 90 days, were BF30, BF60 and BF90, respectively.

\subsection{Methods}

\subsubsection{Morphology Study}

The surface morphologies of the WPF samples, with and without chemical treatment, before and after burial in soil, were examined using scanning electron microscope (SEM, TM3030, Hitachi, Tokyo, Japan). For SEM analyses, all samples were sputter coated with a thin layer of gold and observed using SEM at an accelerating voltage of up to $1.5 \mathrm{kV}$.

\subsubsection{Fourier Transforms Infrared Spectroscopy (FTIR)}

Windmill palm fiber samples, before (WPF, AF, and BF) and after soil degradation (WPF30, WPF60, WPF90, AF30, AF60, AF90, BF30, BF60, and BF90), were subjected to FTIR analyses (Perki-Elmer, Waltham, MA, USA). The spectra were obtained for wave numbers ranging between 4000 and $400 \mathrm{~cm}^{-1}$.

\subsubsection{X-ray Diffraction Analysis}

X-ray diffractograms of windmill palm fiber, before and after degradation, were obtained using an X-ray powder diffractometer (Xpert-Pro MPD, PANalytical B.V., Almelo, The Netherlands). The test was operated at room temperature, using a $\mathrm{Cu}-\mathrm{K} \alpha$ source $(\lambda=1.54 \mathrm{~nm})$ for $2 \theta$ between $5^{\circ}$ and $45^{\circ}$. The crystallinity index was calculated according to the following equation: $\mathrm{CrI} \%=\left[\left(I_{002}-I_{\mathrm{am}}\right) / I_{002}\right]$ $\times 100$. Where $I_{002}$ shows that the peak intensity of the main crystalline plane diffraction was located 
at about $22^{\circ}$, and $I_{\mathrm{am}}$ shows that the intensity of the amorphous fraction materials was observed at about $18^{\circ}$.

\subsubsection{Mechanical Testing}

The tensile properties of windmill palm fiber samples were measured using a universal testing machine (Instron 5967, Instron, Norwood, MA, USA). The load capacity was $500 \mathrm{~N}$ and the cross-head speed was $0.05 \mathrm{~mm} / \mathrm{s}$; gauge lengths of $20 \mathrm{~mm}, 30 \mathrm{~mm}$, and $40 \mathrm{~mm}$ were used. For each sample, the tensile strength of 5 fibers was measured for each gauge length in order to analyze the tensile modulus, tensile strength, and elongation at break, according to the ASTM C1557 "Standard Test Method for Tensile Strength and Young's Modulus of Fibers" [17].

\subsubsection{Soil Burial Degradation}

Three samples $(2 \mathrm{~g}$ ) of each kind of fiber were buried in soil. The biodegradability of the samples, buried in the soil of a garden, were assessed by measuring the rate of residual mass. After drying and weighing, samples were wrapped with 200 mesh and were buried in garden soil at a depth of $20 \mathrm{~cm}$. The $\mathrm{pH}$ of the soil was 8.1, and the particle size distribution of the clay soil was between $122 \mathrm{~nm}$ and $1110 \mathrm{~nm}$. The moisture content of the soil was $15.83 \%$. The buried samples were carefully withdrawn after being buried for 30,60, and 90 days, respectively. Then, the samples were washed with distilled water and dried to a constant weight, at $50{ }^{\circ} \mathrm{C}$ in a vacuum oven. The rate of residual mass (\%) was calculated using the formula: Rate of residual mass $\%=W_{t} / W_{\mathrm{o}} \times 100$. Where $W_{\mathrm{o}}$ is the weight of the sample before biodegradation, and $W_{t}$ is the weight of the sample after biodegradation (at time $t$ ).

\section{Results and Discussion}

\subsection{Analysis of Windmill Palm Fiber Morphology Structure}

SEM micrographs of the surface of windmill palm fiber samples, before and after being buried in soil for different times, are shown in Figure 1. The attached parenchyma cells of the WPFs had coarse surfaces (Figure 1a). Under the parenchyma cells were silica-bodies [14]. After 30 days, the degradation removed the parenchyma cells and silica-bodies. Only conical-shaped circles remained (Figure 1b). Inorganic substances from the soil were physically attached to the surface of windmill palm fiber after 60 days (Figure 1c). This situation worsened as the time went on. After 90 days, the fiber surface was coated with a thick layer of inorganic substances (Figure 1d).

After alkali treatment, a large number of droplets, containing lignin, were observed on the alkali-treated windmill palm fiber surface, as is shown in Figure 1e [15]. These droplets almost disappeared after the fiber was buried in soil for 30 days (Figure 1f). As with the raw windmill palm fiber, a thin layer of inorganic substances covered the fiber surface after 60 days (Figure $1 \mathrm{~g}$ ) and it was thicker after 90 days (Figure $1 \mathrm{~h}$ ).

It can be seen in Figure $1 \mathrm{i}$ that the bleached windmill palm fiber had a striated surface. This is the result of the delignification process exposing the single fibers, and the removal of attached parenchyma cells, silica-bodies, and most of the hemicellulose. After 30 days, the cell wall of the single fibers had been partially degraded (Figure 1j). Several grooves were found on the surface of windmill palm fiber indicating further degradation of the single fiber cell wall. After 90 days, a large number of grooves showed the serious degradation of palm fiber (Figure 11). 


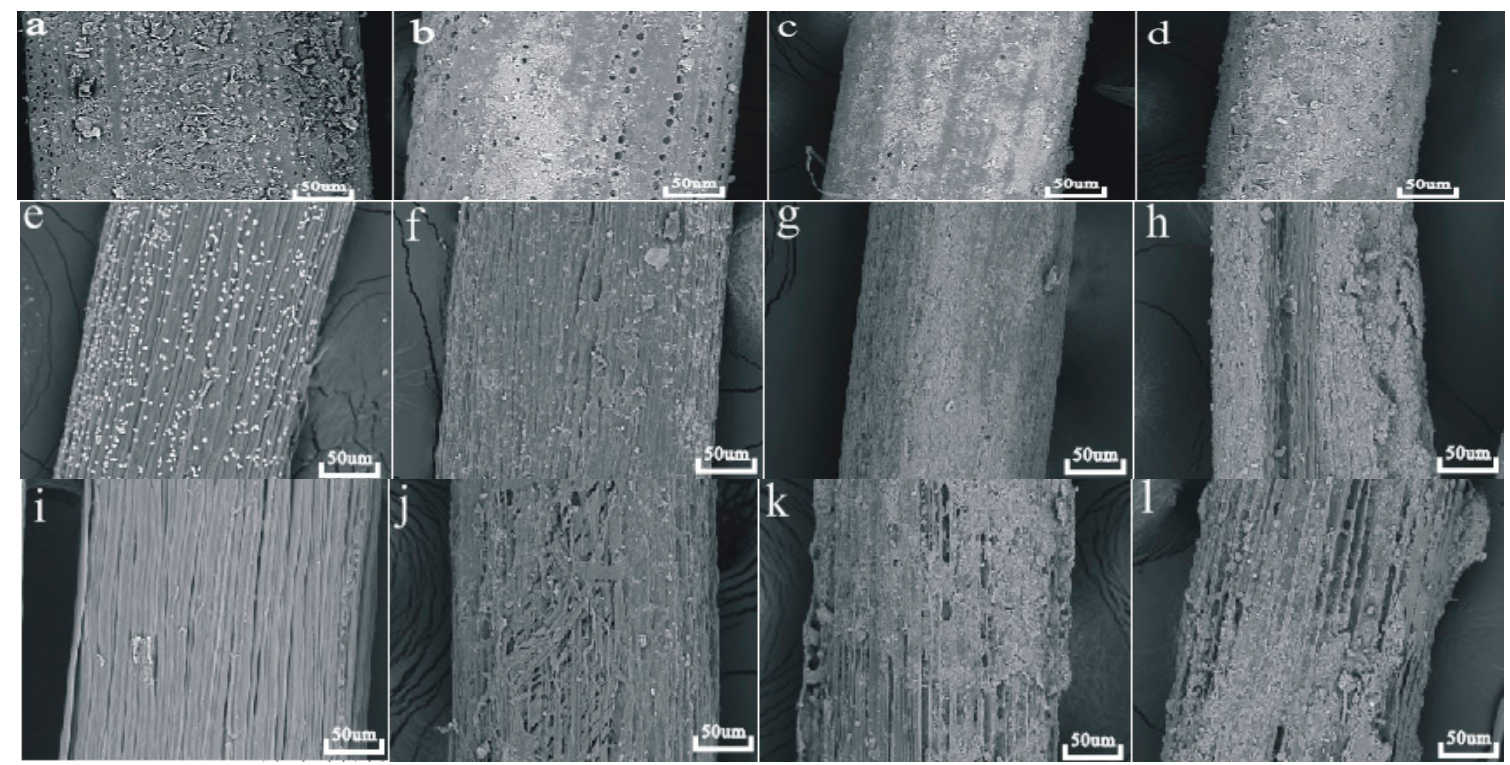

Figure 1. SEM images of the surface morphologies of windmill palm fibers, before and after 30-, 60-, and 90-day soil burial. Untreated windmill palm fiber (a); after biodegradation in soil for 30 days (WPF30) (b); 60 days (WPF60) (c); and 90 days (WPF90) (d). Alkali-treated fibers (AF) (e); after biodegradation in soil for 30 days (AF30) (f); 60 days (AF60) (g); and 90 days (AF90) (h). Bleached fibers (BF) (i); after biodegradation in soil for 30 days (BF30) (j); 60 days (BF60) (k); and 90 days (BF90) (1).

\subsection{FTIR Structural Analyses}

The changes in the functional group that occurred in the WPF, before and after soil degradation, are shown in Figure 2. The peak at about $1740 \mathrm{~cm}^{-1}$ indicated the presence of $\mathrm{C}=\mathrm{O}$ stretching in the acetyl groups of hemicelluloses [18,19]. The peak disappeared at $1741 \mathrm{~cm}^{-1}$ for AF, which indicated the removal of hemicelluloses by the alkali treatment. Likewise, samples AF30, AF60 and AF90 were free of hemicellulose. The absence of the $1741 \mathrm{~cm}^{-1}$ band of BF and WPF can be seen after soil degradation for 60 and 90 days, respectively. This indicates the almost total degradation of hemicellulose in windmill palm fibers.
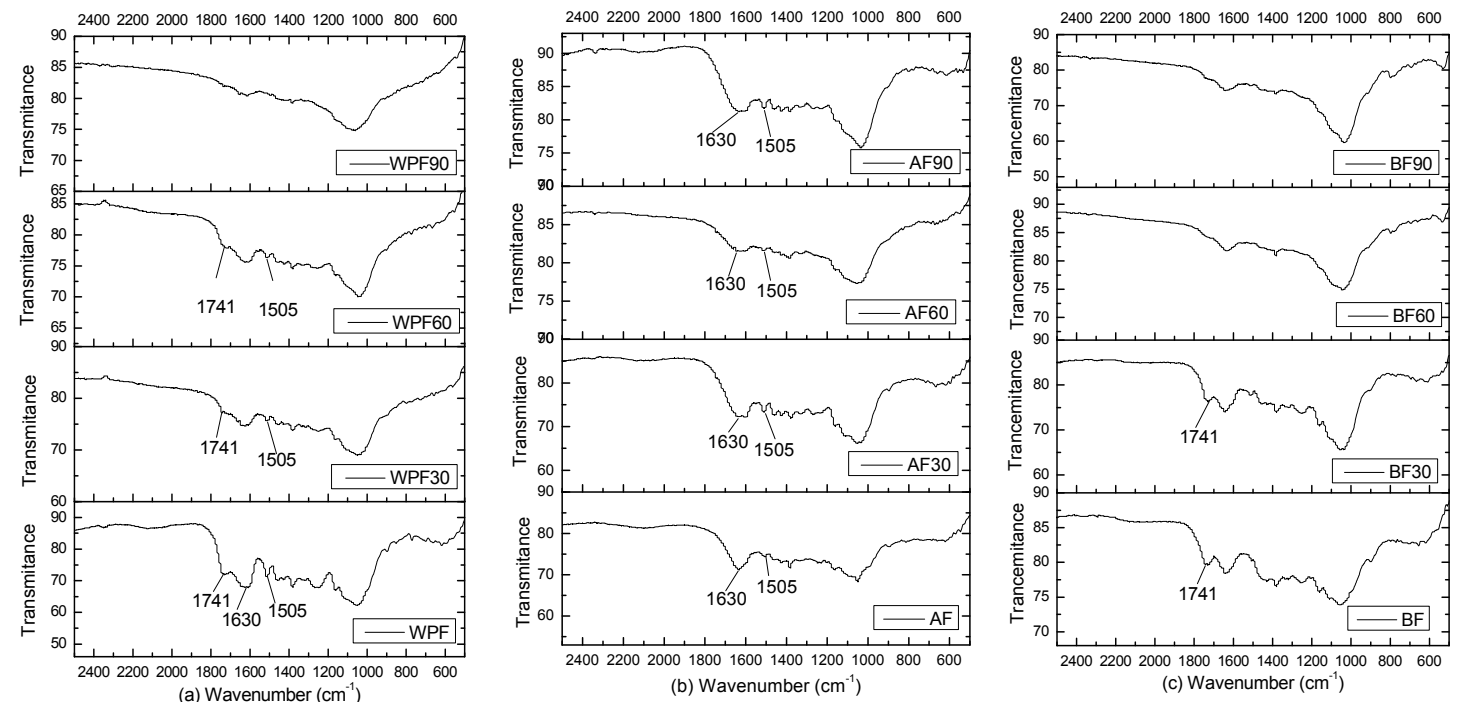

Figure 2. Fourier Transforms Infrared (FT-IR) spectra of (a) windmill palm fiber (b) alkali-treated fiber and (c) bleached fiber before and after biodegradation. 
The band at $1505 \mathrm{~cm}^{-1}$ of BF was gradually reduced with a bleach treatment, which indicated the reduction of lignin content [20-22]. The absence of the FTIR spectra band of WPF90 indicated that no lignin was present in the sample; the AF90 sample still had a clear band at $1505 \mathrm{~cm}^{-1}$. This indicates the slower degradation rate of lignin compared to hemicellulose (when buried in soil). The peak at $1630 \mathrm{~cm}^{-1}$ was due to the characteristic axial vibrations of the hydroxyl group of cellulose [23]. Reduction of this peak intensity is indicative of cellulose degradation. Our results show a complete disappearance of the $1630 \mathrm{~cm}^{-1}$ peak for the BF sample, while it is still visible for the WPF and AF samples. This suggests a faster degradation of cellulose for the bleached sample.

\subsection{X-ray Diffraction and Crystallinity Measurements}

Figure 3 shows the typical XRD diffractogram patterns of cellulose I. The spectra of windmill palm fiber, before and after soil degradation, showed two major reflections corresponding to the $2 \theta$ values of $18^{\circ}$ (amorphous phase) and $22^{\circ}$ (crystallographic plane of cellulose I) [24]. AF60, BF60, WPF90, AF90, and BF90 showed narrow diffractions peaks, attributed to an unknown contamination. The longer the burial time, the more intense the narrow peak. The peak about $26^{\circ}$ may be the inorganic substances from the soil that attached to the fiber surface. Guimarães observed these narrow peaks at $26^{\circ}$ in banana fiber, and correlated them to an inorganic substance [25]. Pereira also believed that the narrow peaks at about $26^{\circ}$ correlated to the salts of inorganic components, such as potassium, chloride, calcium, and phosphor [26].
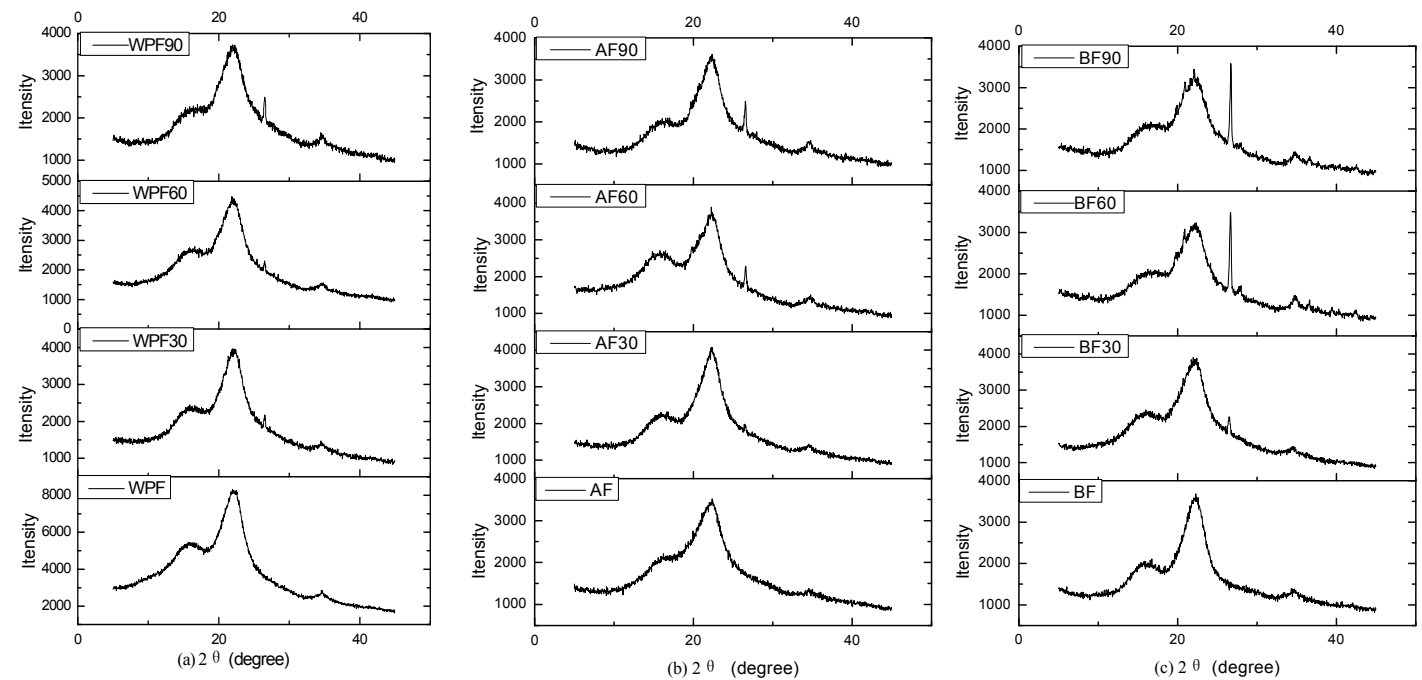

Figure 3. X-ray diffractograms for (a) windmill palm fiber (b) alkali-treated fiber and (c) bleached fiber before and after soil burial.

The crystallinity index of each sample was calculated, and the results are shown in Table 1. The crystallinity index of WPF was $34 \%$; this value increased to $50 \%$ after bleach treatment. After being buried in soil for 30 days, the crystallinity of both WPF30 and AF30 increased due to the degradation of amorphous materials. However, the crystallinity of BF30 decreased to $43 \%$ and the degradation of cellulose may be the reason for these decreases, which would be consistent with the obtained results (Figure 1j). The decrease in crystallinity continues for all the samples in soil for 60 days, but does not seem to continue beyond that. 
Table 1. Crystallinity of windmill palm fiber, before and after degradation.

\begin{tabular}{|c|c|c|c|c|c|}
\hline Samples & 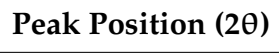 & $I_{002}(\mathrm{cps})$ & 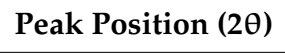 & Iam (cps) & CrI (\%) \\
\hline WPF & 21.61 & 3148 & 18.10 & 2093 & 34 \\
\hline WPF30 & 22.06 & 3894 & 18.47 & 2276 & 42 \\
\hline WPF60 & 22.09 & 4342 & 18.18 & 2549 & 41 \\
\hline WPF90 & 22.09 & 3666 & 17.94 & 2169 & 41 \\
\hline $\mathrm{AF}$ & 22.33 & 3434 & 17.82 & 2065 & 40 \\
\hline AF30 & 22.37 & 4026 & 18.27 & 2118 & 47 \\
\hline AF60 & 22.29 & 3710 & 18.50 & 2315 & 38 \\
\hline AF90 & 22.26 & 3458 & 17.78 & 2157 & 38 \\
\hline BF & 22.34 & 3574 & 18.46 & 1801 & 50 \\
\hline BF30 & 22.26 & 3802 & 18.19 & 2184 & 43 \\
\hline BF60 & 22.25 & 3125 & 18.62 & 1962 & 37 \\
\hline BF90 & 22.17 & 3240 & 18.58 & 2019 & 38 \\
\hline
\end{tabular}

\subsection{Tensile Property Analyses}

Figure 4 shows the tensile properties of windmill palm fiber, before and after soil degradation. The mechanical properties of windmill palm fiber treated using alkali or bleach treatment have been discussed in previous work [15]. The tensile strength of WPF increased by $30 \%$ after the alkali treatment, which is probably due to the removal of hemicellulose and some impurities and the decrease of the fiber diameter. The tensile strength of AF30 and BF30 decreased the most relative to AF60, BF60, AF90, and BF90.

The tensile strength, as well as the elongation at break, showed a linear decrease of about $50 \mathrm{MPa}$ and $5 \%$ per 30 days for AF30, AF60, and AF90. The tensile strength and elongation at break for the bleached samples after soil burial for 90 days decreased by around $43 \%$ and $38 \%$ compared with those of BF. The tensile modulus for windmill palm fiber, alkali-treated fiber, and bleached fiber, before and after biodegradation, showed little difference. Additionally, the results were about $3 \mathrm{GPa}, 8 \mathrm{GPa}$ and $4 \mathrm{GPa}$, respectively.

In order to improve the mechanical properties of wood plastic composites, lignocellulose fiber has been treated by different chemical treatments (especially alkalize treatment) $[27,28]$. Our results showed that alkalize treatment can improve the tensile property, but decrease the durable property at the same time. For the seriously decrease of tensile strength at the first 30 days.
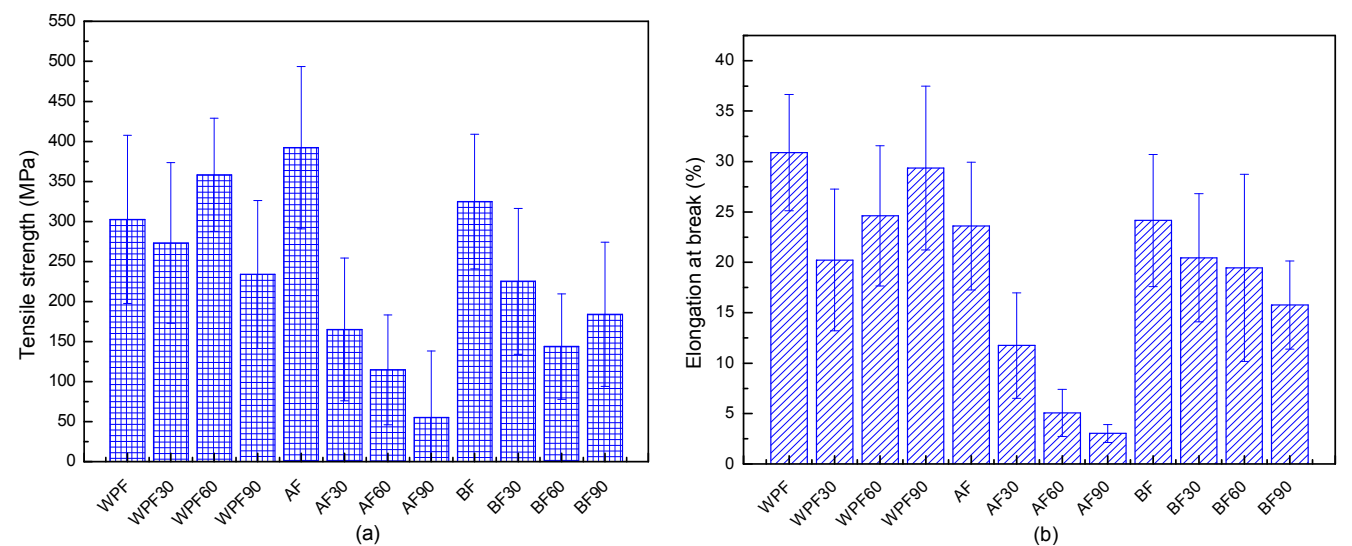

(b)

Figure 4. (a) Tensile strength and (b) elongation at break of windmill palm fiber with and without chemical treatment before and after soil burial.

The analysis results for the mean tensile strength and elongation at break for windmill palm fiber, before and after degradation, are shown in Table 2. After the fiber was buried in soil for 30 days, only the alkali treated fiber experienced a significant tensile strength loss. This may indicate serious 
structural damage to the alkali-treated fiber. WPF and WPF30, as well as the BF and BF30 showed no significant differences. Elongation at break for WPF and WPF30, as well as AF and AF30, had significant differences. A significant difference for bleached fiber can be seen until 60 days. The strain increases with the decrease in micro-fibril angle. The decrease in the elongation at break may indicate that soil burial increases the micro-fibril angle.

Table 2. Analyses of the mean tensile strength and elongation at break for windmill palm fiber, before and after degradation.

\begin{tabular}{|c|c|c|c|c|c|c|c|c|}
\hline \multicolumn{9}{|c|}{ Tensile Strength } \\
\hline \multirow{2}{*}{ Samples } & \multirow{2}{*}{$\mathbf{N}$} & \multicolumn{7}{|c|}{ Subset of Alpha = 0.05} \\
\hline & & 1 & 2 & 3 & 4 & 5 & 6 & 7 \\
\hline AF90 & 15 & 88.5742 & & & & & & \\
\hline AF60 & 15 & 114.7384 & 114.7384 & & & & & \\
\hline BF60 & 15 & 163.7056 & 163.7056 & 163.7056 & & & & \\
\hline AF30 & 15 & 165.1365 & 165.1365 & 165.1365 & & & & \\
\hline BF90 & 15 & & 183.9735 & 183.9735 & & & & \\
\hline BF30 & 15 & & & 225.1725 & 225.1725 & & & \\
\hline WPF90 & 15 & & & 233.801 & 233.801 & & & \\
\hline WPF30 & 15 & & & & 273.1758 & 273.1758 & & \\
\hline WPF & 15 & & & & 291.5799 & 291.5799 & 291.5799 & \\
\hline $\mathrm{BF}$ & 15 & & & & & 328.2119 & 328.2119 & 328.2119 \\
\hline WPF60 & 15 & & & & & & 358.308 & 358.308 \\
\hline $\mathrm{AF}$ & 15 & & & & & & & 390.5304 \\
\hline Sig. & & 0.059 & 0.089 & 0.093 & 0.103 & 0.163 & 0.09 & 0.113 \\
\hline \multicolumn{9}{|c|}{ Elongation at Break } \\
\hline AF90 & 15 & 3.0213 & & & & & & \\
\hline AF60 & 15 & 5.0593 & & & & & & \\
\hline AF30 & 15 & & 11.748 & & & & & \\
\hline BF90 & 15 & & 15.7653 & 15.7653 & & & & \\
\hline BF60 & 15 & & & 19.452 & & & & \\
\hline WPF30 & 15 & & & 20.2353 & 20.2353 & & & \\
\hline BF30 & 15 & & & 20.442 & 20.442 & & & \\
\hline WPF60 & 15 & & & & 24.6113 & 24.6113 & & \\
\hline $\mathrm{AF}$ & 15 & & & & 24.8583 & 24.8583 & & \\
\hline $\mathrm{BF}$ & 15 & & & & 24.9913 & 24.9913 & & \\
\hline WPF90 & 15 & & & & & 29.3487 & 29.3487 & \\
\hline WPF & 15 & & & & & & 31.0407 & \\
\hline Sig. & & 0.374 & 0.081 & 0.062 & 0.064 & 0.059 & 0.46 & \\
\hline
\end{tabular}

\subsection{Mass Loss in Soil}

Figure 5 shows the residual mass rate of windmill palm fiber samples, before and after being buried in soil for different lengths of time. In general, the biodegradation of polymers may involve a number of different steps, including deterioration by decomposing organisms and/or abiotic factors, depolymerization with the reduction in molecular weight, and assimilation [29]. Almost all periods showed mass loss; WPF showed no observable changes in terms of mass. Almost $97 \%$ of the residues remained at 90 days for the untreated windmill palm fiber, from the garden soil burying experiment, 
suggesting that WPF possess a fairly good durable property. After 30 days of soil burial, AF30 and BF30 exhibited the most severe signs of degradation, with a significant mass loss of about $30 \%$ and $20 \%$, respectively. This was in good agreement with the tensile property observations for the most severe signs of tensile strength loss, which also occurs in the first 30 days for AF30 (58\%) and BF30 (31\%).

Note that weight loss shows an approximately linear relation with degradation time for both $\mathrm{AF}$ and $\mathrm{BF}$, with an average degradation rate about $0.4 \%$ day and $0.5 \% /$ day, respectively. It was observed that the residual mass of AF was higher than that of BF at the 60- and 90-day points. The structural complexity of lignin, its high molecular weight, and its insolubility make its degradation very difficult [30]. The AF with lignin has a worse biodegradation than that of BF. The residual mass of BF90 is about $55 \%$, indicating a preferential biodegradation property.

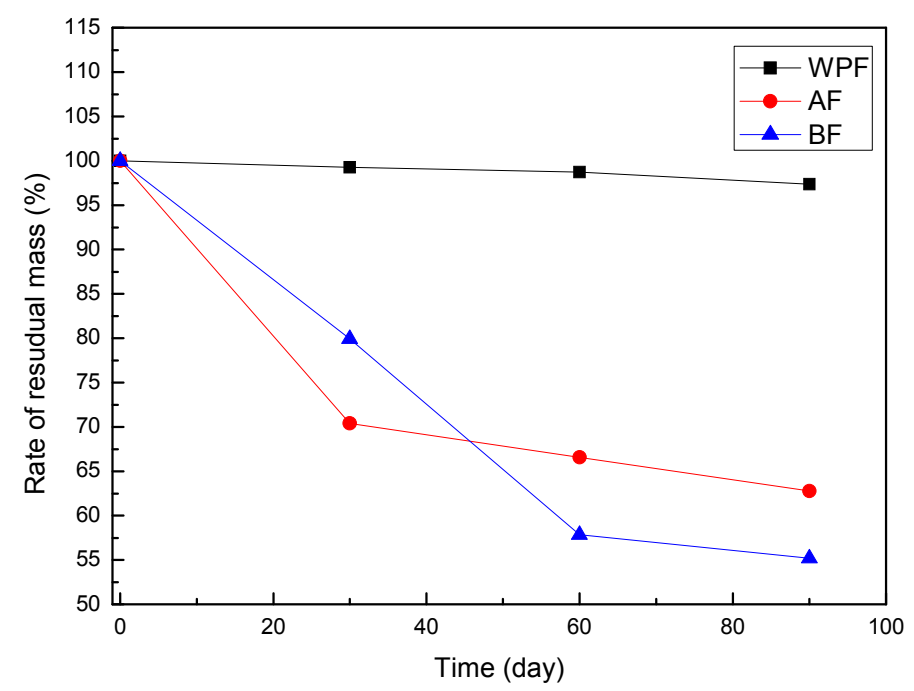

Figure 5. Rate of residual mass of windmill palm fiber (WPF), alkali-treated fiber (AF), and bleached fiber (BF), before and after biodegradation.

\section{Conclusions}

In this study, the surface morphology, chemical composition, crystallinity degree, mechanical properties, and residual mass rate of samples, before and after biodegradation, were investigated. The soil burial degradation removed parenchyma cells and silica-bodies from WPF, as well as droplets containing lignin, from the surface of AF in the first 30 days. In a natural soil environment, hemicellulose showed a faster degradation rate relative to lignin (AF90 still contained lignin, while BF60 was nearly without hemicellulose). This was especially true in the absence of lignin (Disappearance of hemicellulose in BF60 compare to WPF60), therefore, Lignin acted to protect the hemicellulose.

The crystallinity index of BF increased to $50 \%$, as the bleach treatment removed the hemicellulose. The crystallinity degree of WPF30 and AF30 increased to $42 \%$ and $47 \%$, respectively, for the degradation of amorphous materials; however, the crystallinity degree of BF30 decreased to $43 \%$ due to the decrease in cellulose. During the last 30 days (from 60 to 90 days), a lower loss of mass as well as the relatively stable crystallinity degree indicated a slower degradation of fiber. The coated thick layer of inorganic substances may decrease biodegradation.

The tensile strength and elongation at break for the bleached samples after soil burial for 90 days decreased by about $43 \%$ and 38\% compared with those of BF. The AF30 and BF30 samples exhibited the most severe signs of degradation, with a significant mass loss of about $30 \%$ and $20 \%$, which was in accordance with the severe signs of tensile strength loss for AF30 (58\%) and BF30 (31\%). Overall the results were showing that the integrity of the fiber is important for increase biodegradation as appearance of grooves, loss of mass and mechanical properties decreases only happen with bleach and alkalize treatment. 
Acknowledgments: Financial support from the Priority Academic Program Development of Jiangsu Higher Education Institutions, China (No. 37 [2014]) is gratefully acknowledged. This research was funded in part by the Jiangsu Province Special Project, China (No. BY2014083).

Author Contributions: Changjie Chen and Guohe Wang conceived and designed the experiments; Changjie Chen and Weiwei Yin performed the experiments; Changjie Chen and Guangxiang Sun analyzed the data; Guicui Chen contributed reagents/materials/analysis tools; Changjie Chen wrote the paper.

Conflicts of Interest: The authors declare no conflict of interest.

\section{References}

1. Habibi, Y.; Lucia, L.A.; Rojas, O.J. Cellulose nanocrystals: Chemistry, self assembling, and applications. Chem. Rev. 2010, 110, 3479-3500. [CrossRef] [PubMed]

2. Qiu, X.; Tao, S.; Ren, X.; Hu, S. Modified cellulose films with controlled permeatability and biodegradability by crosslinking with toluene diisocyanate under homogeneous conditions. Carbohydr. Polym. 2012, 88, 1272-1280. [CrossRef]

3. Qing, Y.; Cai, Z.; Wu, Y.; Yao, C.; Wu, Q.; Li, X. Facile preparation of optically transparent and hydrophobic cellulose nanofibril composite films. Ind. Crops Prod. 2015, 77, 13-20. [CrossRef]

4. Ibrahim, M.M.; El-Zawawy, W.K.; Jüttke, Y.; Koschella, A.; Heinze, T. Cellulose and microcrystalline cellulose from rice straw and banana plant waste: Preparation and characterization. Cellulose 2013, 20, 2403-2416. [CrossRef]

5. Azubuike, C.; Okhamafe, A.O.; Falodun, A. Some Pharmacopoeial and diluent-binder properties of cellulose derived from maize cob in selected tablet formulations. J. Chem. Pharm. Res. 2011, 3, 481-488.

6. Abraham, E.; Deepa, B.; Pothan, L.A.; Jacob, M.; Thomas, S.; Cvelbar, U.; Anandjiwala, R. Extraction of nanocellulose fibrils from lignocellulosic fibres: A novel approach. Carbohydr. Polym. 2011, 86, 1468-1475. [CrossRef]

7. Kalia, S.; Kaith, B.S.; Kaur, I. Pretreatments of natural fibers and their application as reinforcing material in polymer composites-A review. Polym. Eng. Sci. 2009, 49, 1253-1272. [CrossRef]

8. Kabir, M.M.; Wang, H.; Lau, K.T.; Cardona, F. Chemical treatments on plant-based natural fibre reinforced polymer composites: An overview. Compos. Part B Eng. 2012, 43, 2883-2892. [CrossRef]

9. Wu, C.M.; Lai, W.Y.; Wang, C.Y. Effects of Surface Modification on the Mechanical Properties of Flax/ $\beta$-Polypropylene Composites. Materials 2016, 9, 314. [CrossRef]

10. Wang, X.; Hu, J.; Liang, Y.; Zeng, J. TCF bleaching character of soda-anthraquinone pulp from oil palm frond. BioResources 2011, 7, 0275-0282.

11. Zhu, J.; Zhu, H.; Njuguna, J.; Abhyankar, H. Recent development of flax fibres and their reinforced composites based on different polymeric matrices. Materials 2013, 6, 5171-5198. [CrossRef]

12. Zaman, H.U.; Khan, M.A.; Khan, R.A. Physico-mechanical and degradation properties of banana fiber/LDPE composites: Effect of acrylic monomer and starch. Compos. Interfaces 2011, 18, 685-700. [CrossRef]

13. Zaman, H.U.; Beg, M.D.H. Banana fiber strands-reinforced polymer matrix composites. Compos. Interfaces 2016, 23, 281-295. [CrossRef]

14. Chen, C.J.; Zhang, Y.; Jia, J.J.; Wang, M.X.; Wang, G.H. Morphology Research of Windmill Palm (Trachycarpus fortunei) Material. Kem. U Ind. 2015, 9, 10-14.

15. Chen, C.; Chen, G.; Li, X.; Guo, H.; Wang, G. The influence of chemical treatment on the mechanical properties of windmill palm fiber. Cellulose 2017, 24, 1611-1620. [CrossRef]

16. Khan, G.M.A.; Shams, M.S.A.; Kabir, M.R.; Gafur, M.A.; Terano, M.; Alam, M.S. Influence of chemical treatment on the properties of banana stem fiber and banana stem fiber/coir hybrid fiber reinforced maleic anhydride grafted polypropylene/low-density polyethylene composites. J. Appl. Polym. Sci. 2013, 128, 1020-1029. [CrossRef]

17. ASTM A. C1557, Standard Test Method for Tensile Strength and Young's Modulus of Fibers; American Society for Testing and Materials: West Conshohocken, PA, USA, 2008.

18. Rout, A.K.; Kar, J.; Jesti, D.K.; Sutar, A.K. Effect of Surface Treatment on the Physical, Chemical, and Mechanical Properties of Palm Tree Leaf Stalk Fibers. BioResources 2016, 11, 4432-4445. [CrossRef]

19. Reddy, K.O.; Uma Maheswari, C.; Muzenda, E.; Shukla, M.; Rajulu, A.V. Extraction and Characterization of Cellulose from Pretreated Ficus (Peepal Tree) Leaf Fibers. J. Nat. Fiber 2016, 3, 54-64. [CrossRef] 
20. Wang, Z.; Yao, Z.; Zhou, J.; Zhang, Y. Reuse of waste cotton cloth for the extraction of cellulose nanocrystals. Carbohydr. Polym. 2017, 157, 945-952. [CrossRef] [PubMed]

21. Mandal, A.; Chakrabarty, D. Isolation of nanocellulose from waste sugarcane bagasse (SCB) and its characterization. Carbohydr. Polym. 2011, 86, 1291-1299. [CrossRef]

22. Erdoğan, U.H.; Seki, Y.; Aydoğdu, G.; Kutlu, B.; Akşit, A. Effect of different surface treatments on the properties of jute. J. Nat. Fibers 2016, 13, 158-171.

23. Mohan, T.P.; Kanny, K. Chemical treatment of sisal fiber using alkali and clay method. Compos. Part A Appl. Sci. Manuf. 2012, 43, 1989-1998. [CrossRef]

24. Lamaming, J.; Hashim, R.; Leh, C.P.; Sulaiman, O. Properties of cellulose nanocrystals from oil palm trunk isolated by total chlorine free method. Carbohydr. Polym. 2016, 156, 409-416. [CrossRef] [PubMed]

25. Guimarães, J.L.; Frollini, E.; Da, S.C.; Wypych, F.; Satyanarayana, K.G. Characterization of banana, sugarcane bagasse and sponge gourd fibers of brazil. Ind. Crops Prod. 2009, 30, 407-415.

26. Pereira, A.L.S.; Nascimento, D.M.D.; Souza, M.D.S.M.; Cassales, A.R.; Morais, J.P.S.; Paula, R.C.M.D. Banana (musa sp. cv. pacovan) pseudostem fibers are composed of varying lignocellulosic composition throughout the diameter. BioResources 2014, 9, 7749. [CrossRef]

27. Liu, D.; Song, J.; Anderson, D.P.; Chang, P.R.; Hua, Y. Bamboo fiber and its reinforced composites: Structure and properties. Cellulose 2012, 19, 1449-1480. [CrossRef]

28. Jumaidin, R.; Sapuan, S.M.; Jawaid, M.; Ishak, M.R.; Sahari, J. Thermal, mechanical, and physical properties of seaweed/sugar palm fibre reinforced thermoplastic sugar palm Starch/Agar hybrid composites. Int. J. Biol. Macromol. 2017, 97, 606-615. [CrossRef] [PubMed]

29. Kalka, S.; Huber, T.; Steinberg, J.; Baronian, K.; Müssig, J.; Staiger, M.P. Biodegradability of all-cellulose composite laminates. Compos. Part A Appl. Sci. Manuf. 2014, 59, 37-44. [CrossRef]

30. Pérez, J.; Muñoz-Dorado, J.; Rubia, T.D.L.; Martínez, J. Biodegradation and biological treatments of cellulose, hemicellulose and lignin: An overview. Int. Microbiol. 2002, 5, 53-63.

(C) 2017 by the authors. Licensee MDPI, Basel, Switzerland. This article is an open access article distributed under the terms and conditions of the Creative Commons Attribution (CC BY) license (http:/ / creativecommons.org/licenses/by/4.0/). 